\title{
Monetary Policy in the Transition to a Zero Federal Deficit
}

\author{
Christopher F. Baum, Boston College \\ Meral Karasulu, Bogazici University
}

Prepared for the conference

"Should Congress Direct the Federal Reserve to Stabilize Prices?"

Durrell Institute of the Harry F. Byrd School of Business

Shenandoah University

Washington, DC

April 14, 1997

\begin{abstract}
In the United States, eradication of persistent federal deficits has won broad bipartisan support. At the same time, political pressures have mounted to strengthen the Federal Reserve's explicit concern with price stability. Proposals under consideration would require a much narrower focus on the part of Fed policymakers, and could be interpreted as targeting the price level rather than a negligible rate of inflation. The deficit-reduction and price-stability policies should be analysed in combination, as reductions in the real interest rate triggered by lower deficits will have an impact on optimal monetary policy with anti-inflation and stabilization objectives.

This paper builds upon the analysis of Orphanides and Wilcox (1996) to evaluate optimal antiinflation policy under a broader set of circumstances than considered in their work. We consider a monetary authority with two instruments--the funds rate (or rate of base money growth) and the discount rate--with the distinction that only movements of the latter are 'credible' alterations of the Fed's policy stance, reflecting reputational effects. The public forms expectations of inflation given realized inflation and the expected progress toward lower inflation, as evidenced by credible policy moves and the gradual eradication of the fiscal deficit.

The interaction between deficit reduction policy and the optimal monetary trajectory is analysed, and the implications for the coordination of these strategies considered via stochastic simulations of the model. The impacts of a price level stabilization target on the Fed and a balanced-budget rule on the fiscal authorities are contrasted with their more flexible counterparts: an inflation target and restriction on deficit spending. Our results indicate that these more stringent political constraints on economic policy could have severe consequences on the ability of the monetary and fiscal authorities to mitigate adverse economic shocks.
\end{abstract}




\section{Introduction}

Over the past decade, a considerable literature has been developing on central banks' appropriate stance toward inflation. As inflation in many industrialized countries has been brought under control--in many cases reduced to low single-digit levels-attention has been focused on the policy actions that might be used to preserve that degree of control and effectively cope with any inflationary pressures. The roles of inflationary expectations and institutional arrangements which perpetuate a given rate of inflation, low or high, have been highlighted in this literature. In the United States and several other OECD economies, legal constraints on the central bank's policy objectives and behavior have been considered, and in some cases put into practice. In some instances, these constraints have been phrased in terms of the aggregate price level, rather than the rate of price inflation. For instance, the Economic Growth and Price Stability Act of 1995, introduced by Rep. Saxton in September 1995 (but not acted upon by the 104th Congress), calls upon the Federal Reserve to establish an explicit numerical definition of "price stability" and maintain monetary policy to effectively promote long-term price stability. Such a mandate would seem to require that price increases would have to be met with deflationary policy to satisfy the constraint. More commonly, low or negligible inflation has been identified as an explicit and sole target of monetary policy.

In this paper, we broaden this debate to take into account the interactions between Federal Reserve anti-inflation policy (either discretionary or mandated) and the simultaneous efforts on the part of the fiscal authorities to drive the Federal deficit to zero within a defined period. This emphasis on fiscal stability has also been

phrased in terms of legislative mandates, but the repeated failure of the Congress to pass such legislation should not be viewed as a lack of resolve to deal with the issue of deficit spending. At this writing, there appears to be broad bipartisan support in both Congress and the Administration to enact a feasible plan to balance the budget 
over a realistic time frame. Although the devil may be in the details, such a plan is likely to be enacted in some form, and will set the stage for other policy actions. We consider monetary policy actions in this context, and consider--as other authors have suggested--that anti-inflation policy must take these fiscal measures into account.

We construct a stylized model of the monetary-fiscal interaction which takes several elements of this process into account: inflationary expectations, the credibility of monetary policy, and the dynamic interactions between progress toward budget balance, the underlying movements of the economy's real interest rate, and monetary responses. Although the model is preliminary, it manages to capture many of the implications of these interactions when applied as a nonlinear constraint to a fairly complex stochastic optimal policy problem. This problem takes as given the progress toward the fiscal goal of budget balance within five to ten years and generates closed-loop feedback rules for the manipulation of two monetary policy instruments, the funds rate and the discount rate, over a 40-quarter horizon.

The plan of the paper is as follows. Section 2 reviews a selection of relevant literature, while the following section presents the econometric model and illustrates its properties. In Section 4, the optimal policy experiment is presented, and implications drawn for the interactions between the fiscal target path and monetary policy responses. Section 5 concludes the paper, and provides a sketch of further research. 


\section{Review of the Literature}

The recent literature on the conduct of monetary policy is vast, and we can only acknowledge the major influences on our work in this paper. The view of monetary policy as a process with identified goals and inherent constraints, rather than a sequence of discretionary actions, underlies the papers in several recent conference volumes. The Boston Fed's "Goals, Guidelines and Constraints Facing Monetary Policymakers" (1994), the Kansas City Fed's symposia "Budget Deficits and Debt: Issues and Options" (1995), "Achieving Price Stability" (1996) and the Bank of Japan's "Financial Stability in a Changing Environment" (1995) all contain papers highlighting the importance of the design of monetary policy and its interaction with the real economy. John Taylor's article in the Boston volume specifically addresses the interactions between the "implicit" real interest rate specified by monetary policymakers and the economy's equilibrium real interest rate. As the latter is altered by policy changes in the real economy--as we discuss in this paper-Taylor demonstrates that the steady-state inflation rate will change, and by more than the equilibrium real rate, requiring a response from monetary policymakers.

William Poole's paper in the same volume is concerned with the choice facing monetary policymakers in using interest rates or monetary aggregates as their instrument. He finds reason for concern for the de facto abandonment of the aggregates as the instrument of policy, arguing that heavy reliance on the funds rate has rendered the financial markets hypersensitive to minor shifts (real or perceived) in the Fed's policy stance. Poole relates that "...the overwhelming majority of large changes in bond yields arise in response to actions by the monetary authorities and to releases of routine economic data." (1994, p.106) This generates, in his view, a situation where "...the Fed cannot use the behavior of interest rates to provide useful information on how it should adjust the federal funds rate. The bond market today tells the Fed what the market thinks the Fed is going to do." (1994, p.108) 
While realization of this dependence may do much to inflate the egos of Fed governors, it also creates a situation where, as Poole puts it, "...it is easy for the Fed to make a mistake because the bond market will not provide a strong contrary signal." (1994, p.108) Thus, monetary policy actions must be taken with a clear understanding of how market participants' expectations will respond to those signals.

In a paper given at the 1995 Kansas City Fed conference, John Taylor specifically considers the interactions between the practice of monetary policy and an environment with greater fiscal discipline. He considers how monetary policymakers' objectives may have to be adjusted during the transition to a lower deficit, and how monetary policymaking might be constrained by the imposition of limits on budget deficits. A crucial distinction--shared by a number of researchers-arises between reducing the structural deficit to zero and prohibiting a deficit at any point in the cycle. Taylor suggests that "...ideal fiscal reform would preserve the cyclical variation in the actual deficit while forcing the structural deficit to be zero..." (1995, p.163) but acknowledges that many of the rules being considered in Congress would actually constrain the total deficit. This severe constraint would force a change in monetary policy, as the "automatic stabilizers" of fiscal policy would be removed by a prohibition on deficit spending. He concludes that fiscal discipline need not have a sizable effect on the credibility of monetary policy, but would have significant benefits for the real economy in the form of higher productivity growth and higher real incomes.

In the Kansas City Fed's symposium on "Achieving Price Stability," Mervyn King considers how central banks should achieve price stability, drawing on his experience at the Bank of England. He considers the distinction between a central bank's ex ante inflation target and its discretionary response to shocks, and suggests that "...in general, it is not optimal to move immediately to a regime of price stability unless that regime can be made fully credible by institutional or other changes." (1996, pp. 57-58) His rationale for that conclusion is based on the 
hypothesis that there are costs of disinflation, increasing more than proportionally in the rate of disinflation, related to private agents' ability to determine whether a regime change has actually taken place. (This argument is very closely related to that put forth by Kozicki and Tinsley $(1996 a, 1996 b)$ in their moving-endpoint models). King argues that "...expectations are likely to be influenced by the committment to price stability among the public at large" (1996, p. 58) and suggests that central bank behavior can only influence that commitment. Private agents must learn about the new economic environment, and the central bank must learn about agents' revised behavior. In King's view, "pure rational expectations models are not a good basis on which to base policy because they ignore the process of learning." (1996, p.79) From his viewpoint, a successful model of monetary policy must take the learning process into account.

In another paper in the same volume, Lars Svensson argues that an explicit inflation target is the best way to maintain low and stable inflation. In this paper and in several others, he puts forth the concept of the inflation forecast as an intermediate target, which in his view avoids the problems of lags, demand and supply shocks, and model uncertainty. Svensson considers the relative merits of "target rules" vs. "instrument rules," preferring the former on the grounds of feasibility and transparency. He also speaks directly to the issue of price level targeting vs. inflation targeting, pointing out an interesting consequence of an insistence on the former: a reduction in variance of the price level (i.e. price stability) will actually imply greater short-term variability of the inflation rate and output. As he argues, "...in order to stabilize the price level under price level targeting, higher-than-average inflation must be followed by lower-than-average inflation. This should result in higher inflation variability than inflation targeting, since base level drift is accepted in the latter case and higher-than-average inflation need only be succeeded by average inflation. Via nominal rigidities, the higher inflation variability should then result in higher output variability." (1996, p.217) 
A different aspect of the interactions between monetary policy and other sectors of the economy is given by participants in the Bank of Japan's conference on financial stability, in which the potentially conflicting objectives of the central bank are highlighted. On the one hand, any central bank has macroeconomic objectives, be they a statutory responsibility for low inflation, a stable price level, or maximum growth and employment consistent with objectives of stable prices. At the same time, central banks serve as regulators in the financial sector, and the policy responses required to counter threats to financial sector stability may run counter to their appropriate macro-policy stance. Charles Goodhart points out that a more prudent regulatory stance--for instance, insisting on market value accounting, which if applied in the 1980s would have rendered many banks and S\&Ls technically insolvent far more rapidly than did regulatory standards of the time--is bound to conflict with macroeconomic objectives; in his words, "most measures aimed at encouraging more prudent bank behavior are liable to be procyclical in the short run, whereas...Central Bank actions to support banks through crises are likely to be anti-cyclical...Regulatory measurs, e.g. capital ratios...tend to bite during (asset price) depressions, and are more commonly non-binding during (bubble) booms." (1995, p.478) Goodhart also argues that one of the common remedies proposed for banking safety, "narrow bank" schemes, would make cyclical fluctuations more extreme through dis- (and re-) intermediation effects over the business cycle.

Writing in the same volume, Bennett McCallum considers the tension between "lender-of-last-resort" functions of the central bank and the call to focus monetary policy on a "macro-oriented rule" (e.g. those advocated by McCallum, Meltzer, or Taylor) such as a mandate for price stability or low inflation. He considers that interest rate smoothing, usually treated as a goal of short-term open market policy, may actually be able to reconcile both objectives, as it "would automatically trigger open-market purchases whenever a sharp increase in the demand for high-powered money happened to occur. But such week-to-week smoothing could perhaps be compatible with use of this interest rate as an instrument for hitting slightly lowerfrequency (e.g. quarterly average) intermediate targets conforming to a monetary 
policy rule designed to yield desirable macroeconomic performance." (1995, p.415) Thus, this strand of literature considers the importance of recognizing these dual objectives in any central bank's mandate, and taking into account the central bank's important role in promoting stability of the financial system when contemplating a single-minded macro objective.

Finally, we must acknowledge the very sizable contribution of a paper by Orphanides and Wilcox (1996) to our development of a model of these policy issues. In their FEDS paper, they introduce the "opportunistic approach" to disinflation: the concept that the Fed may actively combat inflation only when it threatens to increase, and otherwise should wait for external circumstances (e.g. recessions) that will bring the inflation rate down. This approach leads to a switching strategy, in which the Fed acts to stabilize output when inflation is low, but moves to fight inflation when it is high. The definitions of "low" and "high" are state-dependent in their model, so that there is no fixed rule defining the policy response to current conditions. Orphanides and Wilcox provide an appealing argument for this mixed strategy: that is, for the central bank's concern for output and employment. They suggest that the policymakers incur a "first-order loss from output deviations even when output is close to potential, and yet only a second-order loss from inflation deviations when inflation is close to its target." (1996, p.22) They provide what is characterized as a highly speculative rationale for this ordering, in that "The deleterious effects of inflation are mainly allocative in nature..." while "...employment is an all-or-nothing proposition...", providing "the basis for treating deviations of output from potential as imposing first-order costs on the policymaker." (1996, p.23)

They extend their model to consider more realistic aspects of aggregate demand and supply, but their model is cast in a single-period framework. We take a number of elements of their model as a starting point in developing the model presented in the next section, in which we use a multi-period framework in order to consider the dynamic interactions of monetary policy with fiscal discipline. 


\section{A Model of Monetary and Fiscal Interactions}

In this section, the framework we have developed to evaluate the dynamic interactions between anti-inflation monetary policy and a deficit reduction strategy is presented. The model necessarily abstracts from many elements of a complete and interdependent treatment of expectations formation and policy design, but has been constructed to focus on key elements of this process in the context of historical evidence. The model consists of three estimated behavioral equations and a number of identities linking two monetary instruments to the targets of policy. Progress toward the fiscal objective is taken as exogenous; in future work we will relax this recursive structure, and allow for uncertainty in the attainment of fiscal goals. Unlike Orphanides and Wilcox' original work (1996), which is purely analytical, and their followup paper (Orphanides et al., 1996), which performs stochastic simulations in an historical setting, we utilize the model in a closed-loop optimal policy exercise, in which explicit penalties are applied to deviations from target values, and optimal feedback rules derived for the policy instruments.

The policy environment modelled here is one in which Federal Reserve actions can control short-term nominal interest rates, but cannot control real rates. As one of the major innovations of this model, we consider two instruments of monetary policy--the Federal funds rate and the discount rate--which are both assumed to have effects on the financial sector, but differ in their signalling capability. We make use of well-known stylized facts about the discount rate: that it has been altered infrequently, in small increments, and almost never subjected to a reversal (e.g. Baum and Karasulu, 1998). These empirical regularities, coupled with the description of the discount rate by researchers inside and outside the Fed as an instrument with sizable "announcement effects," lead us to a description of policy in which a discount rate change is viewed as a credible signal of the stance of policy, precisely because such a signal is infrequently and cautiously emitted. The funds 
rate, on the other hand, is viewed as an instrument which has direct effects on the financial sector, but is far less credible as a signal of policy stance. Realistically, changes in the funds rate may reflect either the Fed's doing or their acquiescence to market forces--or even an allowed response to a threat to financial system stability. In the stylized environment of our model, we consider that changes in the funds rate are much less effective in influencing inflationary expectations than are discount rate changes.

In this setting, aggregate demand, as proxied by the GDP gap, responds (with some persistence) to movements in the real rate of interest relative to its long-run level; the current real rate is determined by the Fisher equation, incorporating the funds rate. The aggregate supply relation is inverted to generate the level of inflation consistent with the GDP gap and expected inflation. Inflation is modeled as a persistent phenomenon, implicitly reflecting contract terms and menu costs of price adjustment (along the lines of Fuhrer and Moore, 1995). Inflationary expectations are modeled with a partial adjustment scheme, in which both past expectations and recently experienced inflation affect their revision. The deviation of the discount rate from the long-term real rate of interest is used to signal the Fed's willingness to credibly reduce inflation to that level.

On the fiscal side, we make use of the empirical regularity cited by Taylor, in which he cites "A close approximation of current fiscal policy in the United States is that the budget deficit (D) as a share of GDP rises by 0.5 times the percentage deviation (Y) of real GDP from potential GDP...That is, a fiscal policy rule which closely approximates the actual deficit is $D=-0.5 Y+S$ where $S$ is a constant." (1995, p.162) S equals the structural deficit as a share of GDP; Taylor finds that it has been about 3.5 percent over the past decade. Using this regularity, we model fiscal discipline as a trajectory for S which reduces S from its 1995 level to near zero over a range of 20-40 quarters. We consider three trajectories for $S$, differing in the speed at which a zero structural deficit is attained, and in their pattern of reduction. In the current form of the model, we calculate the resulting accounting deficit (D), but it plays no further 
role in the model's workings. In an extension, we plan to take account of the feedback between continued deficits and financing costs, or "crowding out." We also do not take account in this version of the model of the likely obstacles to deficit reduction--political or external--that most sanguine observers of the process might expect to arise. Realistically, such roadblocks would both slow the transition path and create added uncertainty about its likely outcome.

The crucial link between deficit reduction and the financial sector is provided by an equation linking the change in the structural deficit to the change in the long-term real rate of interest. We do not model this as a response to the accounting deficit, as we want to express the long-run equilibrium rate of interest as independent of the business cycle. We make use of estimates presented by Taylor's simulation of his multicountry econometric model, in which a one per cent increase in the deficit/GDP ratio brings about a roughly 50 basis point increase in the long-term bond rate. (1993, pp.202,213-214) We use this estimated response coefficient to project the magnitude of the fall in the equilibrium real interest rate which will be generated by greater fiscal discipline. As Taylor suggests, there is fairly broad consensus that "lower budget deficits will lower real interest rates, increase investment, and thereby increase productivity growth and real incomes" (1995, p.151). As fiscal discipline reduces real interest rates, the monetary policy authorities must take this shifting anchor into account when setting their target for inflation.

We now present the estimated relationships and identities of our model, which were fit to quarterly data over the 1975-1995 period. The estimated equation for the GDP gap (defined as $Y=100 \log \left(G D P / G D P^{p}\right)$ where the GDPP series was derived from CBO estimates) is a fourth-order autoregression in the gap augmented with the spread between the current real rate and its long run target. The coefficient estimates are presented in Table 1. The estimated coefficient on the spread has the expected negative sign. This equation is dynamically stable, with a maximum modulus of 0.943. 
Table 1: Estimated Equation for the GDP Gap (Y), 1975:1-1995:4

\begin{tabular}{lccc} 
Regressor & Coefficient & Standard Error & T-ratio \\
\hline $\mathrm{Y}(\mathrm{t}-1)$ & 3.3635 & 0.0684 & 49.18 \\
$\mathrm{Y}(\mathrm{t}-2)$ & -4.5610 & 0.1953 & -23.35 \\
$\mathrm{Y}(\mathrm{t}-3)$ & 2.9594 & 0.1985 & 14.91 \\
$\mathrm{Y}(\mathrm{t}-4)$ & -0.7757 & 0.0716 & -10.83 \\
{$\left[\mathrm{r}-\mathrm{r}^{*}\right]$} & -0.0063 & 0.0025 & -2.53 \\
\hline
\end{tabular}

Notes: estimation method is ordinary least squares with Hansen-White errors.

The estimated equations for realized and expected inflation form a block. Realized inflation--the inverted aggregate supply schedule--is modeled as a fourth-order autoregression augmented with the prior period's expected inflation series and the current GDP gap ratio. Expected inflation is modeled with a lag to account for delays in price-setting behavior. The coefficient estimates of the realized inflation equation are presented in Table 2. Expected inflation stimulates realized inflation, as does a higher value of the GDP gap variable (i.e. a smaller gap). The equation is dynamically stable, with a maximum modulus of 0.924 .

Table 2: Estimated Equation for the Inflation Rate $(\pi), 1975: 1-1995: 4$

\begin{tabular}{lccc} 
Regressor & Coefficient & Standard Error & T-ratio \\
\hline$\pi(\mathrm{t}-1)$ & 0.6261 & 0.1434 & 4.37 \\
$\pi(\mathrm{t}-2)$ & -0.1833 & 0.2027 & -0.90 \\
$\pi(\mathrm{t}-3)$ & 0.5515 & 0.1530 & 3.60 \\
$\pi(\mathrm{t}-4)$ & -0.1182 & 0.1304 & -0.91 \\
$\pi^{\varepsilon}(\tau-1)$ & 0.1051 & 0.2723 & 0.39 \\
$\mathrm{Y}(\mathrm{t})$ & 0.1708 & 0.1117 & 1.53 \\
\hline
\end{tabular}

Notes: estimation method is ordinary least squares with Hansen-White errors.

Expected inflation is modeled with a partial adjustment mechanism, in which a convex combination of lagged expected inflation and inflationary influences generates expectations. The influences considered include once- and twice-lagged actual inflation as well as the spread between the discount rate and the long-term real rate. As discussed above, the latter term is introduced to proxy for credible policy 
signals; a larger spread indicates that the Fed is willing to allow higher inflation to persist, while a narrowing of the spread would indicate an attack on inflation, in this framework perceived as credible. The coefficient estimates, obtained by nonlinear least squares, are presented in Table 3. A fairly high weight is placed upon current inflationary influences, and the effect of the spread is sizable and significant.

Table 3: Estimated Equation for the Expected Inflation Rate $\left(\pi^{\varepsilon}\right), 1975: 1-1995: 4$

$$
\pi_{t}^{e}=\lambda \pi_{t-1}^{e}+(1-\lambda)\left(\eta_{1} \pi_{t-1}+\eta_{2} \pi_{t-2}+\eta_{3}\left(d_{t}-r_{t}^{*}\right)\right)
$$

\begin{tabular}{lccc} 
& Coefficient & Standard Error & T-ratio \\
\hline$\lambda$ & 0.1801 & 0.2090 & 0.86 \\
$\eta_{1}$ & 0.7136 & 0.1274 & 5.60 \\
$\eta_{2}$ & 0.0403 & 0.1527 & 0.26 \\
$\eta_{3}$ & 0.2183 & 0.0948 & 2.30 \\
\hline
\end{tabular}

Notes: estimation method is nonlinear least squares with Hansen-White errors.

The expected inflation series used in these estimates was generated from a projection of realized inflation on eight lags of inflation, the GDP gap, the two policy instruments and a constant term. This series was then used to define the current real rate $(R)$ as the difference between the Fed funds rate and expected inflation. The long term real rate, which enters the first two behavioral equations, was estimated as the sample mean of $\mathrm{R}$ over the period, equal to 2.21 percent.

To evaluate the reasonableness of the entire model, an ex ante dynamic simulation was performed for 1996:1-2005:4. Monetary policy instruments were held at their 1995:4 values, while the structural deficit (S) was projected to decline linearly from its historical value of 3.65 percent of GDP to zero over the 40 quarter horizon. Resulting trajectories of the model's variables were sensible, with a modest loss of output (reaching just over two percent of GDP at the end of the horizon) and a steady reduction in realized and expected inflation. The single anomaly in this simulation was the accounting deficit, which fell only slowly through the period, never falling below one percent of GDP. Thus, the simulation does not reflect a true 
balanced budget rule, but rather an exercise in which the structural deficit is eradicated over the 10-year horizon. In summary, the model would appear to be reasonably well behaved, and capable of being used in an out-of-sample period to reflect the interactions of the real and financial sectors in the context of fiscal discipline and anti-inflation policy.

\section{Optimal Monetary Policy Responses to Fiscal Discipline}

The framework in which we pose an optimal policy problem is that developed by Chow $(1975,1981)$ as an elaboration of the stochastic, dynamic linear-quadraticGaussian (LQG) optimal control framework. In a standard LQG exercise, the expectation of a multiperiod quadratic loss function is minimized, subject to the constraints posed by a linear econometric model, with stochastic elements arising from Gaussian errors. The solution is achieved by solution of the matrix Riccati equation, applying Bellman's principle of dynamic programming to generate optimal feedback rules for each period in the horizon. This framework is unduly restrictive in terms of both the loss function and the econometric model, as on the one hand we might often want to penalize deviations from targets in a nonquadratic (e.g. asymmetric) manner, and on the other hand we might have a model which is essentially nonlinear. Extensions to Chow's algorithm permit both of these generalizations by generating linearizations of a nonlinear model around each point on the target trajectory. A nonlinear model may contain complicated (and even nondifferentiable, or noncontinuous) functions of the underlying variables, which may then be targeted--allowing for nonquadratic elements in the loss function. With these generalizations of the LQG framework, we may consider a quite realistic setting for the interactions of policy instruments and goals.

The key elements of such an optimal policy problem are the relative weights applied to the components of the state vector. In the Chow framework, the dynamic system of arbitrary order in both endogenous $(\mathrm{Y})$ and policy $(\mathrm{X})$ variables is reduced to first 
order via the introduction of appropriate identities. In the case of our model, there are up to fourth-order lags on the $\mathrm{Y}$ variables, and as noted below, up to third-order lags on the $X$ variables are referenced. Thus the state vector for this model consists of current through third-order lags on the $\mathrm{Y}$ variables (which, with identities and definitions, are 14 in number) and current through second-order lags on the two $\mathrm{X}$ variables. In a stochastic optimal policy exercise, the existence of more than two targeted elements of the state vector ensures that not all targets will be hit even in an expected sense. The expected multiperiod loss may be considered similar to a measure of mean square error (MSE), including both a "bias" term (indicating the magnitude in which the targets were not hit) and a "variance" term derived from the estimated variance-covariance matrix of the equations' error processes. Although in this framework the parameters are taken as given at their point estimates (i.e. there is no multiplicative uncertainty) the presence of additive uncertainty will generate expected loss even when "bias" is zero.

The loss function applied in this problem is an extension of that used by Orphanides and Wilcox (1996, p.7) in their one-period model. They include three terms in their loss function $\ell_{a}=(\pi-\tilde{\pi})^{2}+\gamma y^{2}+\psi|y|$ : the squared deviation of realized inflation from an inflation target, the squared GDP gap, and the absolute value of the GDP gap. The presence of the intermediate target for inflation, which they treat as merely a constant fraction of last period's inflation, and the weighting of both square and absolute value of the GDP gap give rise to their "opportunistic approach" to antiinflation policy. They also demonstrate that the inflation term in their loss function is mathematically equivalent to targeting both the level of and changes in the rate of inflation--or in terms of the control literature, applying both proportional and derivative control.

In our policy problem, we are facing a multiperiod horizon, and have two instruments to work with. Our loss function takes additional factors into account, reflecting the more complex setting in which these instruments interact. The 
primary innovation in our multiple-instrument setting is the specification of loss associated with discount rate changes. As discussed above, we assume that changes in the discount rate are viewed as credible signals of policy stance by the public. The maintenance of this credibility relies upon the Fed's willingness to alter the instrument infrequently and to avoid reversals, or "whipsaw" actions. Although we cannot directly model the degree of credibility attached to a signal in the expectations formation process, we can take the maintenance of credibility into account in the loss function. The Fed, aware of the value of a credible signalling mechanism, should be unwilling to reduce this value through haphazard manipulations of the discount rate. Thus, we construct a "cost-of-change" variable (C) which takes into account both recent changes in the discount rate as well as the consistency of those changes--penalizing reversals more heavily than changes which merely reflect a trend, such as successive increases (decreases). The $C$ function is defined as:

$$
\begin{aligned}
& c c_{t}=\left|\log \left(d_{t} / d_{t-1}\right)\right|+0.5\left|\log \left(d_{t} / d_{t-2}\right)\right|+0.333\left|\log \left(d_{t} / d_{t-3}\right)\right| \\
& r c 1_{t}=\left\{\begin{array}{cc}
\log \left(d_{t} / d_{t-1}\right)-\log \left(d_{t-1} / d_{t-2}\right) \mid, & \left(d_{t}-d_{t-1}\right)\left(d_{t-1}-d_{t-2}\right)<0 \\
0, & \left(d_{t}-d_{t-1}\right)\left(d_{t-1}-d_{t-2}\right) \geq 0
\end{array}\right. \\
& r c 2_{t}=\left\{\begin{array}{cc}
0.5\left|\log \left(d_{t} / d_{t-2}\right)-\log \left(d_{t-2} / d_{t-3}\right)\right|, & \left(d_{t}-d_{t-2}\right)\left(d_{t-2}-d_{t-3}\right)<0 \\
0, & \left(d_{t}-d_{t-2}\right)\left(d_{t-2}-d_{t-3}\right) \geq 0
\end{array}\right. \\
& C_{t}=c c_{t}+r c 1_{t}+r c 2_{t}
\end{aligned}
$$

The value of this cost-of-change variable is then targeted as an element of the loss function. To gain an understanding for the workings of the cost-of-change function, we plot its components (change cost and reversal cost) and their sum for the estimation period, 1975:1-1995:4, in Figure 1, and the total cost versus the discount rate in Figure 2. We may note that the Fed's actions, involving quite infrequent and consistent changes in the discount rate, correspond to a quite low cost throughout much of the historical period. 
Two other elements derived from the policy instruments are targeted: the spread between the funds rate and the discount rate, and the spread between the current real rate and its long-run target. The rationale for the former relates to the mechanism by which the discount rate will provide incentives for member bank borrowing. The funds rate-discount rate spread is generally positive, reflecting that discount window borrowing is a privilege, and that "excessive" use of the discount windows will invite scrutiny. Therefore, banks with the need for reserves will turn to the Fed funds and repurchase agreement (RP) markets, paying a premium to conduct transactions free of this scrutiny. To model this empirical regularity, we target the funds rate-discount rate spread at 30 basis points, a value consistent with recent historical evidence. The latter spread--that between the current real rate and its long-run value--is targeted merely as a direct effect to speed convergence of the real rate to its long-run value.

In the policy experiment, the heaviest weight of 1.0 is placed on the squared deviation of current inflation from its target value, reflecting the Fed's primary concern with the reduction of inflation. Following Orphanides and Wilcox, the intermediate target for inflation is taken to be 0.5 times last period's inflation, so that the long-run target for inflation is zero. Lower weights of 0.25 are applied to both the squared gap and the absolute value of the gap, with values chosen to generate some tension between anti-inflation and macroeconomic objectives. The cost-of-change function and the two spreads mentioned above are each targeted at 0.10 , reflecting the second-order concern with instruments' values. It should be noted that, first, only relative weights matter, and second, that the magnitude of the variables affects the appropriate magnitude of the weights.

As stated above, we model the trajectory of fiscal discipline as deterministic, reflecting steady progress toward the goal of a zero structural deficit from the initial conditions of 3.65 percent of GDP. In the baseline experiment (denoted 40), the structural deficit is reduced linearly to zero over 40 quarters (the full horizon of the policy experiment). In the first alternative (denoted 20), the structural deficit is 
reduced to zero twice as fast-over the first 20 quarters of the experiment-and held at zero for the remaining period. In the second alternative (denoted CG), the structural deficit is reduced to $92 \%$ of its prior value in each period, with a terminal value close to zero. All other elements of the model are determined within the policy experiments.

The outcome of the policy experiment is a set of optimal feedback rules which express the appropriate settings for the two instruments as a function of the prior period's state vector. In this closed-loop optimal policy setting, the optimal policy is not expressed in terms of values for the instruments, but rather rules by which the instruments would be determined, contingent on economic conditions. The certainty-equivalent trajectory for each of the instruments may be derived by ignoring the stochastic elements of the problem and applying the feedback rules to each period's values for the state vector. These certainty-equivalent trajectories may then be examined to judge the qualitative nature of the optimal policy solution.

In Figure 3, results from the baseline experiment (in which the structural deficit is reduced to zero over 40 quarters) are presented for the GDP gap, the inflation rate, and the deficit/GDP ratio. Although the structural deficit is reduced linearly, the accounting deficit is subject to economic performance. For the first several years of the simulation, the output gap remains at about 0.5 percent of GDP, causing the accounting deficit to be larger than the structural deficit. The inflation rate declines abruptly at the beginning of the experiment, rebounds, and then falls steadily throughout the remaining period, nearing 0.5 percent in the later years. The inflation rate is juxtaposed with the two policy instruments in Figure 4. We see here that attainment of lower inflation brings about lower money-market rates, consistent as well with the reduction in the real rate. The decline in both the funds rate and the discount rate is steep at the outset, but fairly smooth due to the cost-ofchange imposed on the discount rate. 
Figure 5 compares the expected trajectories of the GDP gap for the three deficit reduction strategies: the baseline (40-quarter) case, the 20-quarter alternative, and the constant reduction (CG) alternative. All three provide similar results at the outset, but the more rapid (Y.20) alternative demonstrates an improvement in the gap as soon as the structural deficit is eradicated in 2000. However, in the last two years, it actually underperforms the other scenarios. Equivalent findings for the current real interest rate are presented in Figure 6. The 40-quarter scenario yields the slowest decline in the rate over the period; the rapid balance (r.20) strategy brings about the lowest rates from the third year onward.

In Figure 7, the differing paths of the accounting deficit are presented. The CG alternative may be seen as an intermediate path, leading to the most rapid initial decline but higher accounting deficits from mid-1999 onward. These higher deficits are associated with higher real interest rates; in Figure 8, we may see the difference between the discount rates consistent with each strategy. The discount rate associated with the 40-quarter strategy (DR.40) is consistently higher than that associated with the other strategies, reflecting the necessity for the monetary authorities to coordinate their actions with the imposition of fiscal discipline. To contrast these discount rate paths with those experienced in the estimation period (presented in Figure 2), we illustrate the cost-of-change (C) and the expected trajectory for the discount rate (DR.40) for the baseline scenario in Figure 9. The weight placed upon cost-of-change renders reversals of the rate unlikely; the trajectory is quite smooth, leveling off in the middle years (leading to a lower cost of change) and then dipping downward in the later years.

Although many additional insights might be gleaned from analysis of the optimal policy experiments and variations on those experiments, it should be evident that many elements of the interactions between fiscal discipline, expectations of policy actions, and the policies chosen by the Fed are captured in these results. Although the model presented here is simplistic and stylized, it demonstrates some of the key dynamic elements of the policy process. 


\section{Conclusions and Suggestions for Further Research}

Should the Federal Reserve be instructed to stabilize prices (or the rate of price inflation?) Much of the literature we have reviewed in this study has concluded that the traditional stance of our central bank, evincing concern for both price stability and macroeconomic performance, has merit. In the context of a major fiscal initiative such as a steady course toward eradicating the deficit, it may be all the more important that the Federal Reserve retain some flexibility to counter unforseen shocks, even if they might tend to temporarily weaken the anti-inflation effort. At the same time, flexibility can degenerate into arbitrary, destabilizing policy actions. In this paper, we have stressed the importance of credibility of monetary policy through the introduction of a "credible signal" in the form of the discount rate. The historical manipulation of this policy instrument is consistent, we believe, with the underlying concept embedded in our cost-of-change function: that market participants value a credible signal, and the Fed acts so as to maintain that credibility in manipulating an instrument with a powerful "announcement effect." Although the model constructed here is in its early stages of development, we believe that it successfully demonstrates the dynamic interactions between fiscal and monetary strategies, and its employment in an optimal policy exercise goes beyond the usual simulation experiments.

In further development of this framework, we believe that the Orphanides and Wilcox "opportunistic" approach, which underlies much of the model presented in this paper, and our own work on modelling discount policy may be fruitfully combined. The concept of threshold behavior, in which action is only taken when a threshold is reached, is attractive in the context of a policy instrument whose use incurs a sizable cost. It may be feasible to combine our ad hoc specification of a costof-change function in this paper with an econometric approach to threshold 
modelling in order to generate a more realistic representation of monetary policymakers' actions. 


\section{References}

Baum, C.F. and M. Karasulu, 1998. Modelling Federal Reserve Discount Policy. Computational Economics, forthcoming.

Chow, G., 1975. Analysis and Control of Dynamic Economic Systems. New York: John Wiley and Sons.

Sons.

1981. Econometric Analysis by Control Methods. New York: John Wiley and

Fuhrer, J. and G. Moore, 1995. Inflation Persistence. Quarterly Journal of Economics, 110:127-159.

Goodhart, C.A.E., 1995. Price Stability and Financial Fragility, in K. Sawamoto et al., eds., Financial Stability in a Changing Environment. London: St. Martin's Press.

King, M., 1996. How Should Central Banks Reduce Inflation? Conceptual Issues, in Achieving Price Stability. Kansas City: Federal Reserve Bank of Kansas City.

Kozicki, S. and P. Tinsley, 1996a. Moving endpoints in the term structure of interest rates. Unpublished working paper, Federal Reserve Bank of Kansas City.

and 1996b. Moving endpoints and the Internal Consistency of

Agents' Ex Ante Forecasts. Unpublished working paper, Federal Reserve Bank of Kansas City.

McCallum, B., 1995. Monetary Policy Rules and Financial Stability, in K. Sawamoto et al., eds., Financial Stability in a Changing Environment. London: St. Martin's Press.

Orphanides, A. and D. Wilcox, 1996. The Opportunistic Approach to Disinflation. FEDS Working Paper 96-24, Federal Reserve Board.

Orphanides, A. et al., 1996. A Quantitative Exploration of the Opportunistic Approach to Disinflation. Unpublished working paper.

Poole, W., 1994. Monetary Aggregates Targeting in a Low-Inflation Economy, in J. Fuhrer, ed., Goals, Guidelines and Constraints Facing Monetary Policymakers. Boston: Federal Reserve Bank of Boston.

Svensson, L., 1996. Commentary on "How should monetary policy respond to shocks while maintaining long run price stability-conceptual issues," in Achieving Price Stability. Kansas City: Federal Reserve Bank of Kansas City. 
Taylor, J., 1993. Macroeconomic Policy in a World Economy. New York: W.W. Norton. 1994. The Inflation/Output Variability Trade-off Revisited, in J. Fuhrer, ed., Goals, Guidelines and Constraints Facing Monetary Policymakers. Boston: Federal Reserve Bank of Boston. 1995. Monetary Policy Implications of Greater Fiscal Discipline, in Budget Deficits and Debt: Issues and Options. Kansas City: Federal Reserve Bank of Kansas City. 
Figure 1

Cost of Change Function for the Discount Rate, 1975-1995

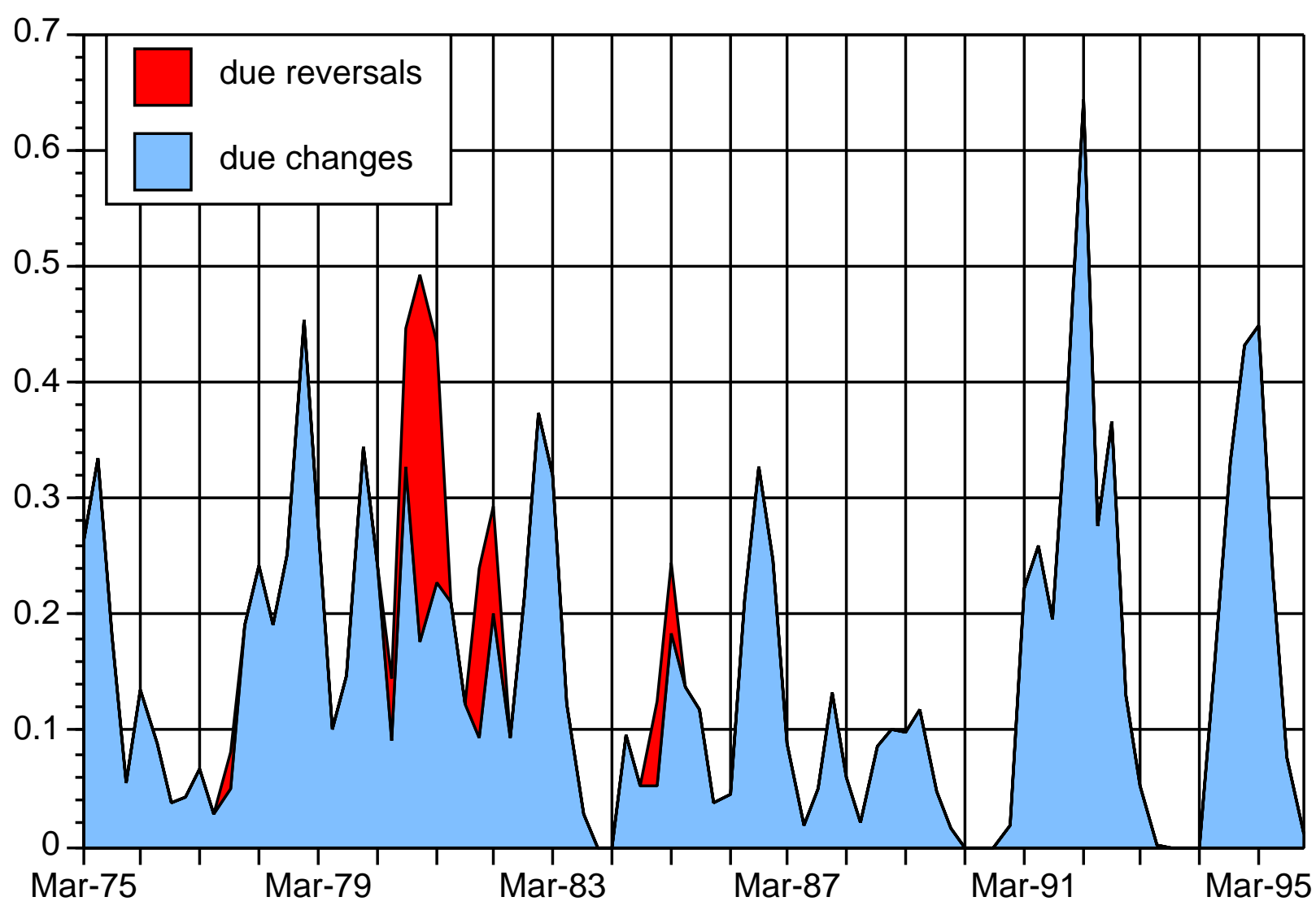


Figure 2

Cost of Change Function and the Discount Rate, 1975-1995

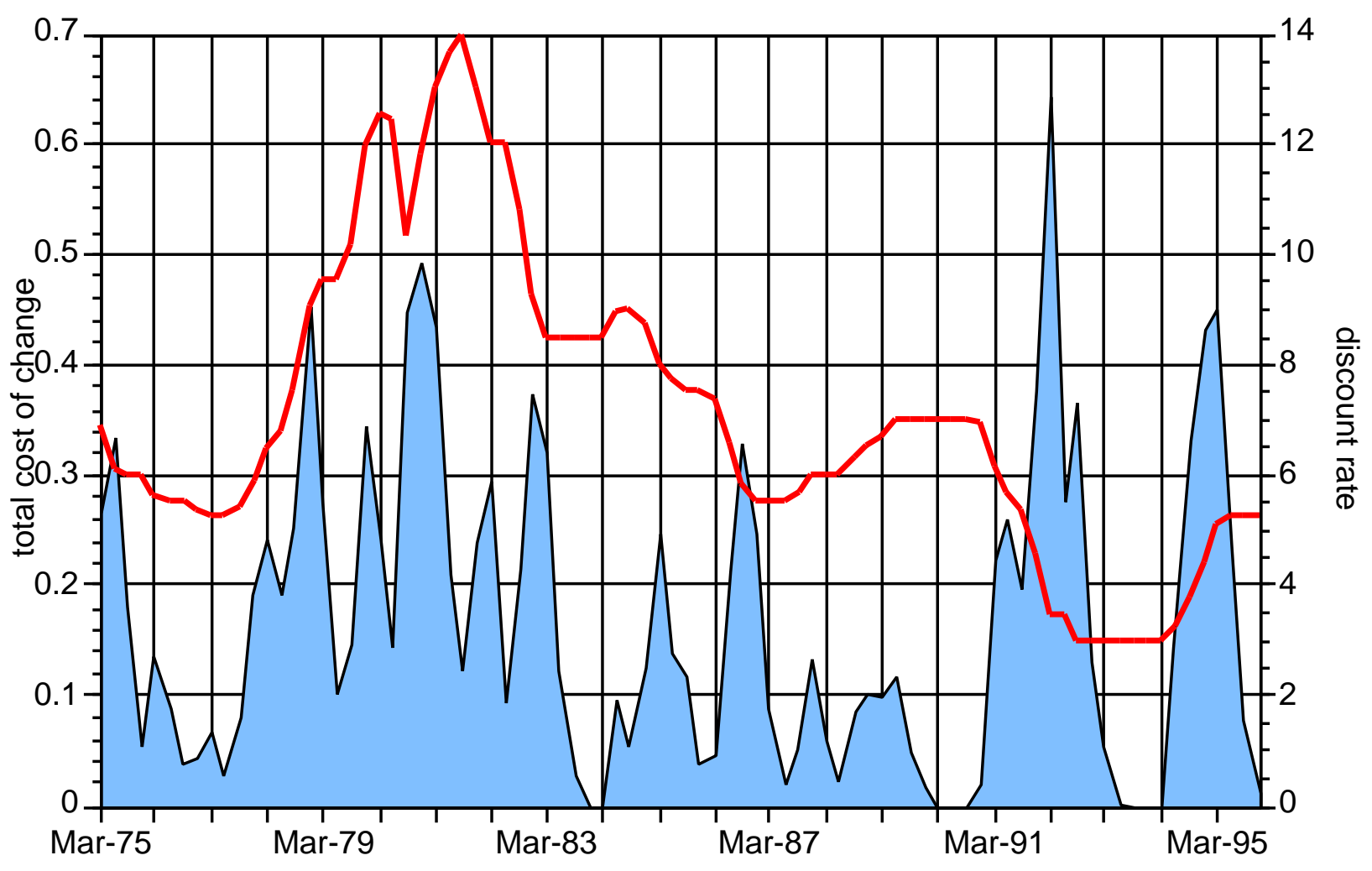


Figure 3

GDP Gap, Inflation Rate, and Deficit/GDP Ratio, baseline experiment

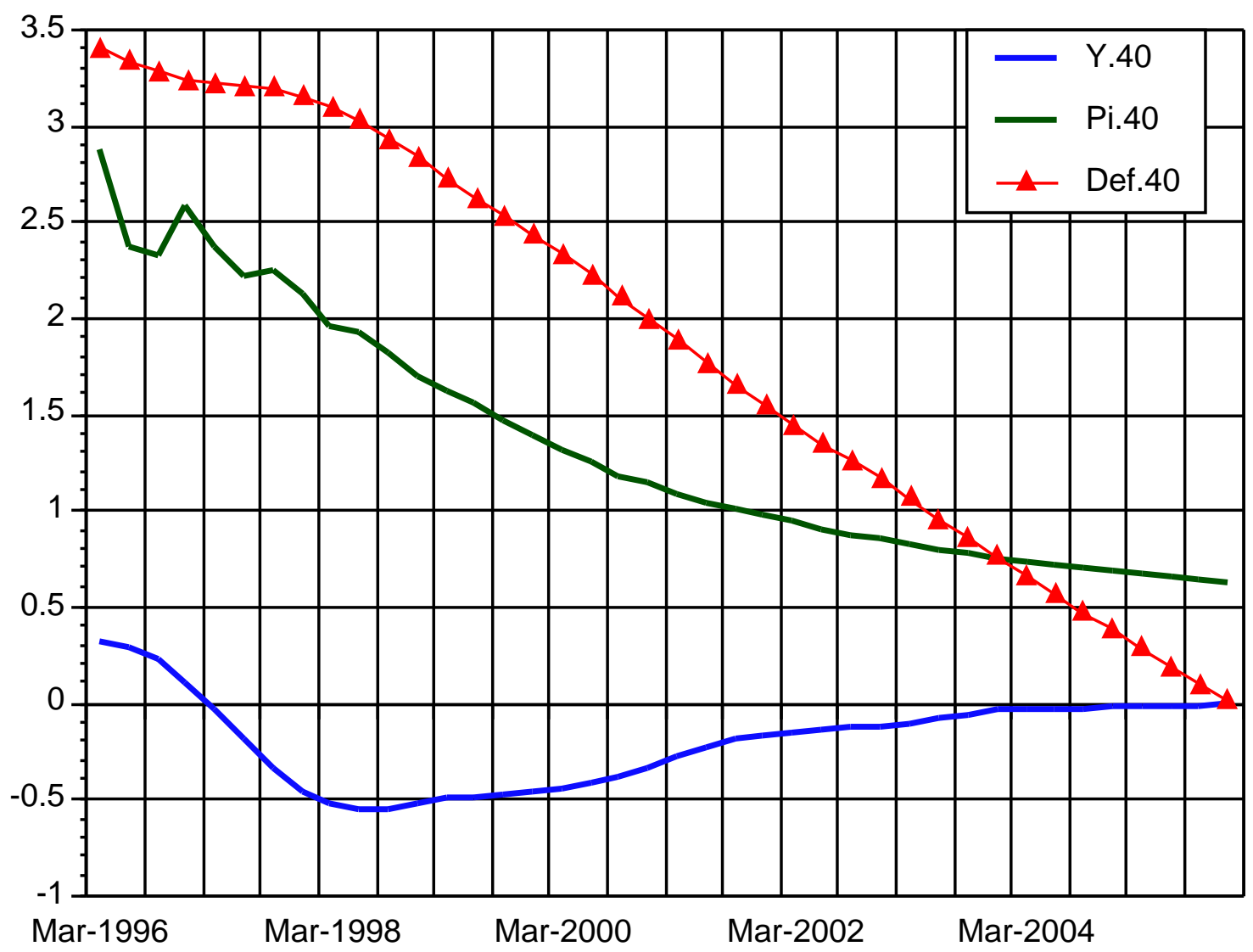


Figure 4

Inflation Rate, Fed Funds Rate, and Discount Rate, baseline experiment

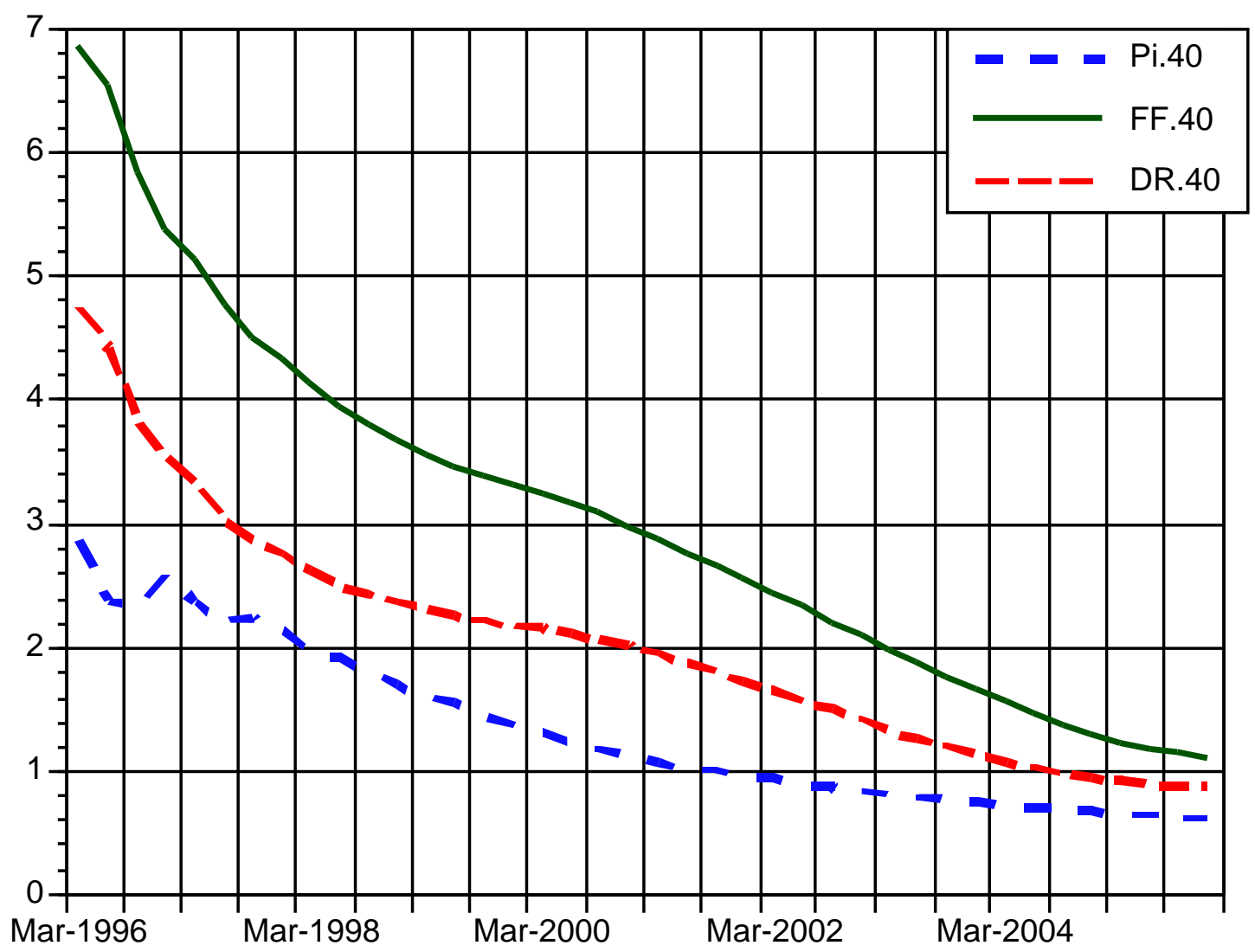


Figure 5

GDP gap for alternate deficit reduction strategies

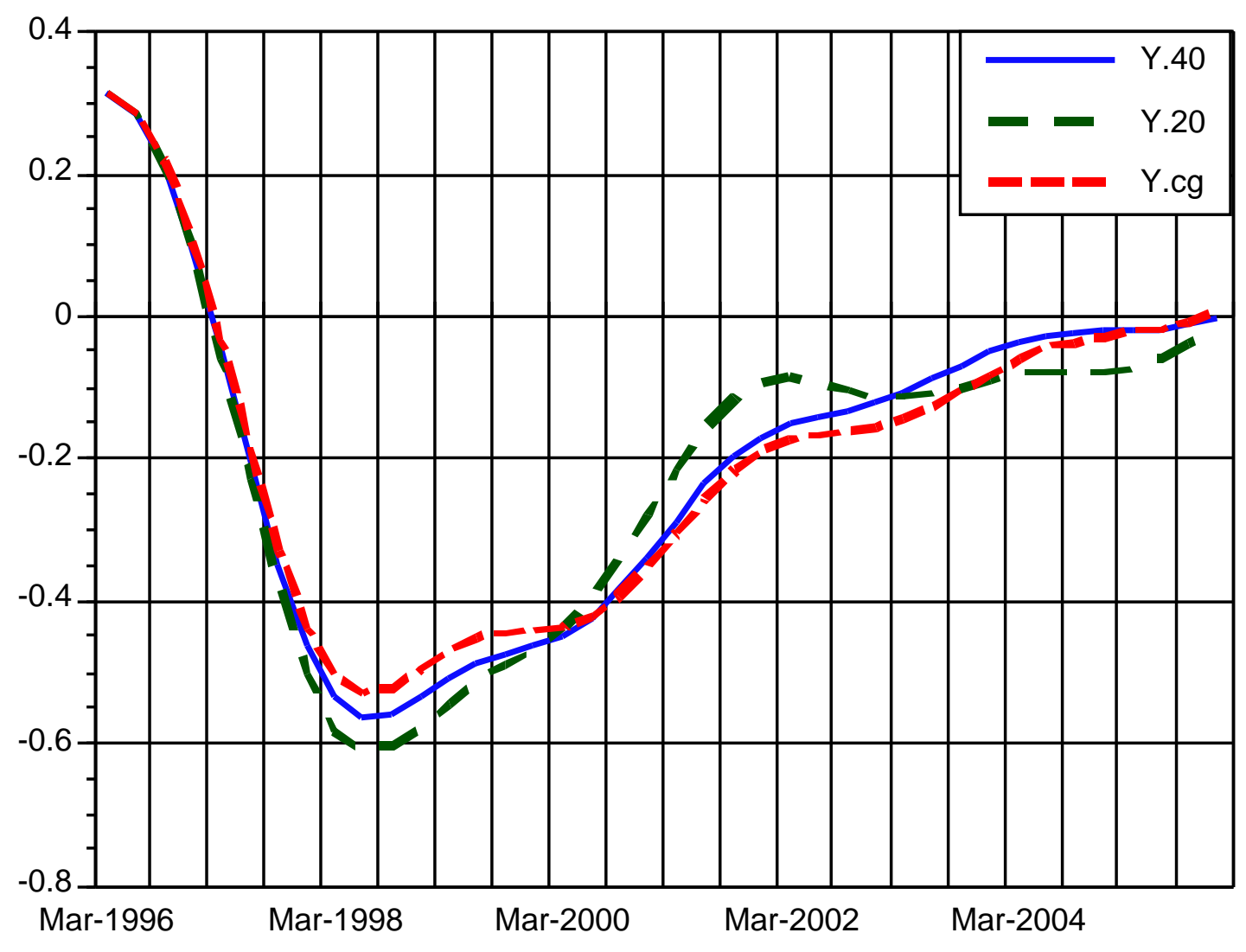


Figure 6

Real Interest Rate for alternate deficit reduction strategies

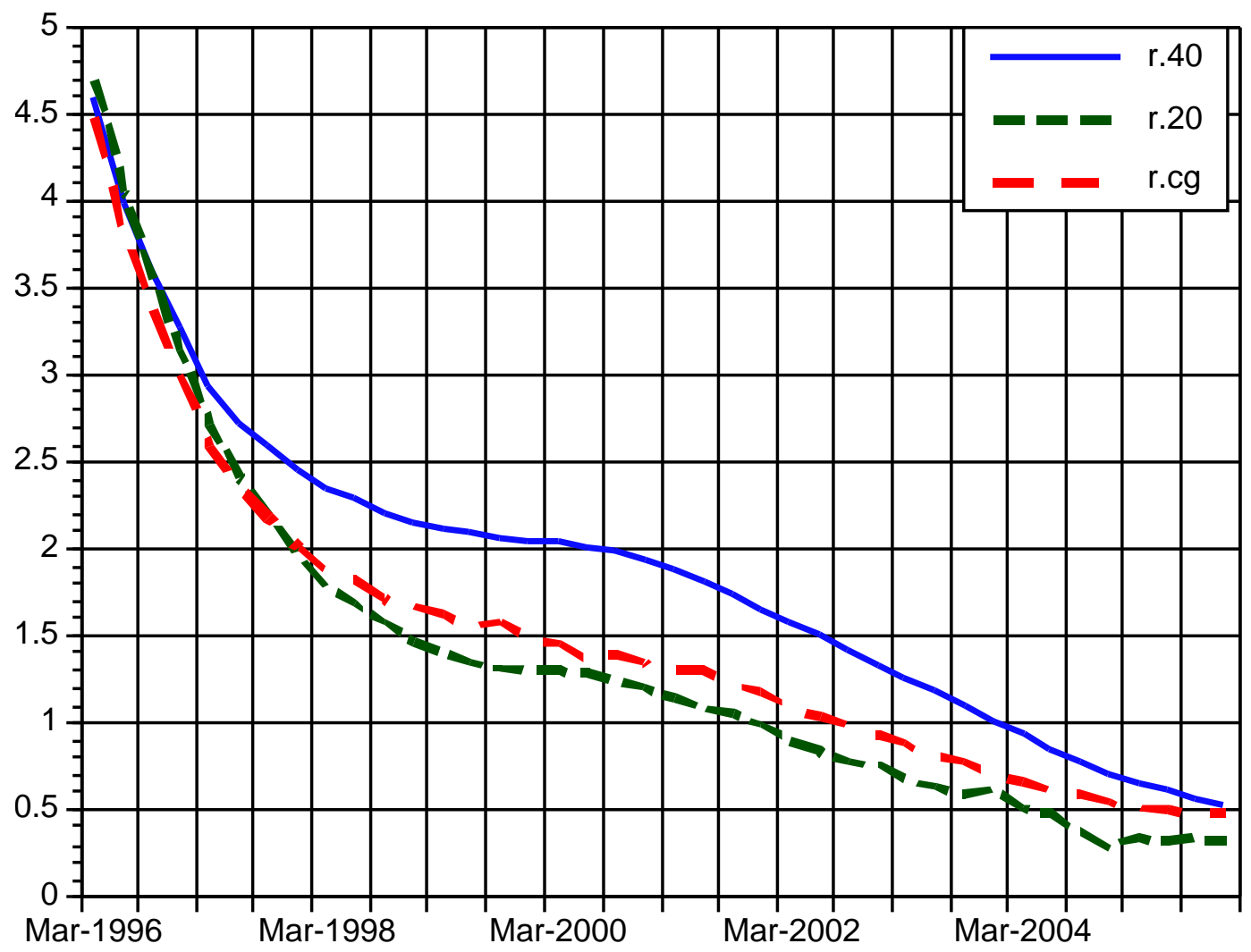


Figure 7

Accounting Deficit/GDP for alternate deficit reduction strategies

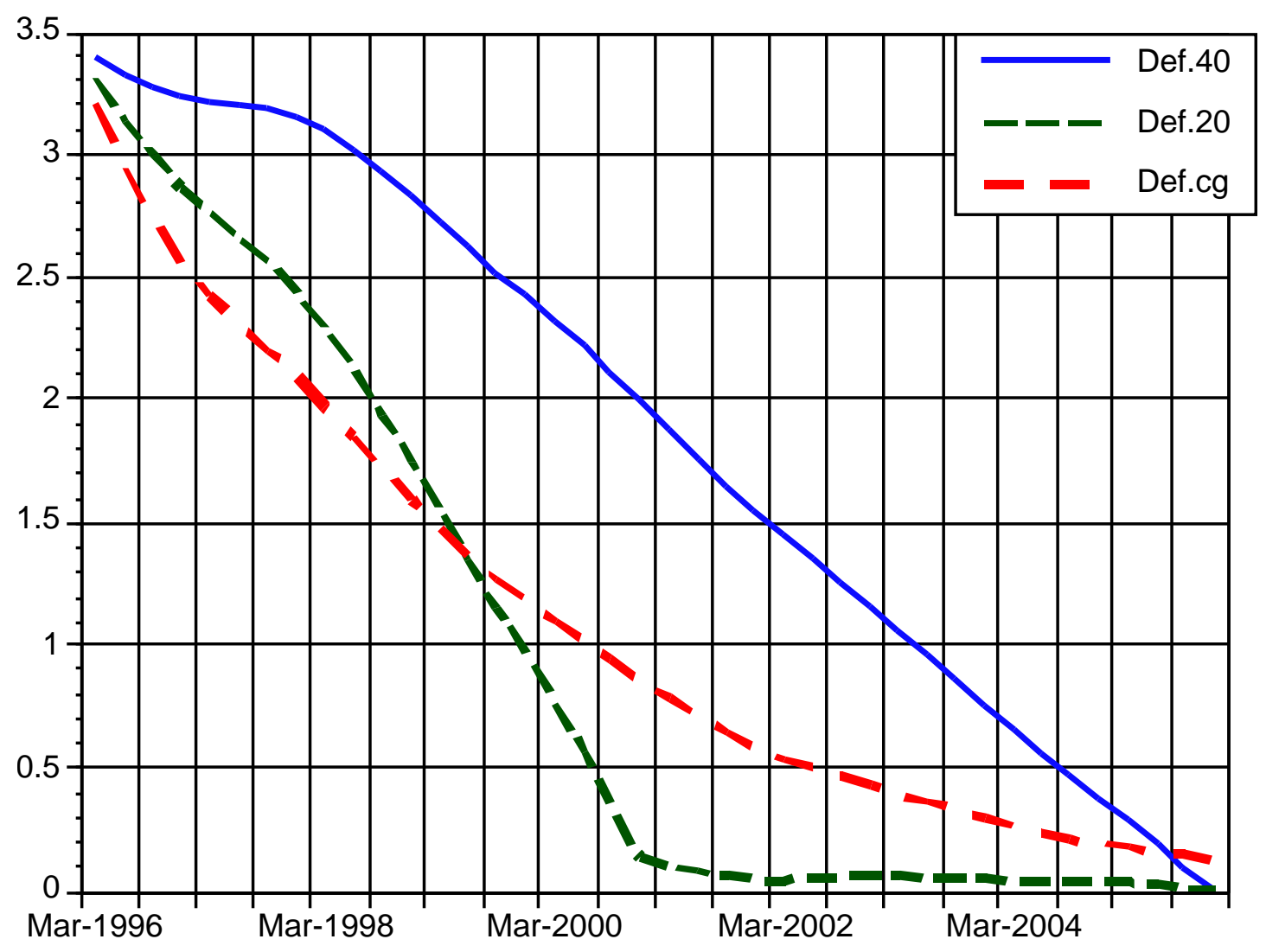


Figure 8

Discount Rate for alternate deficit reduction strategies

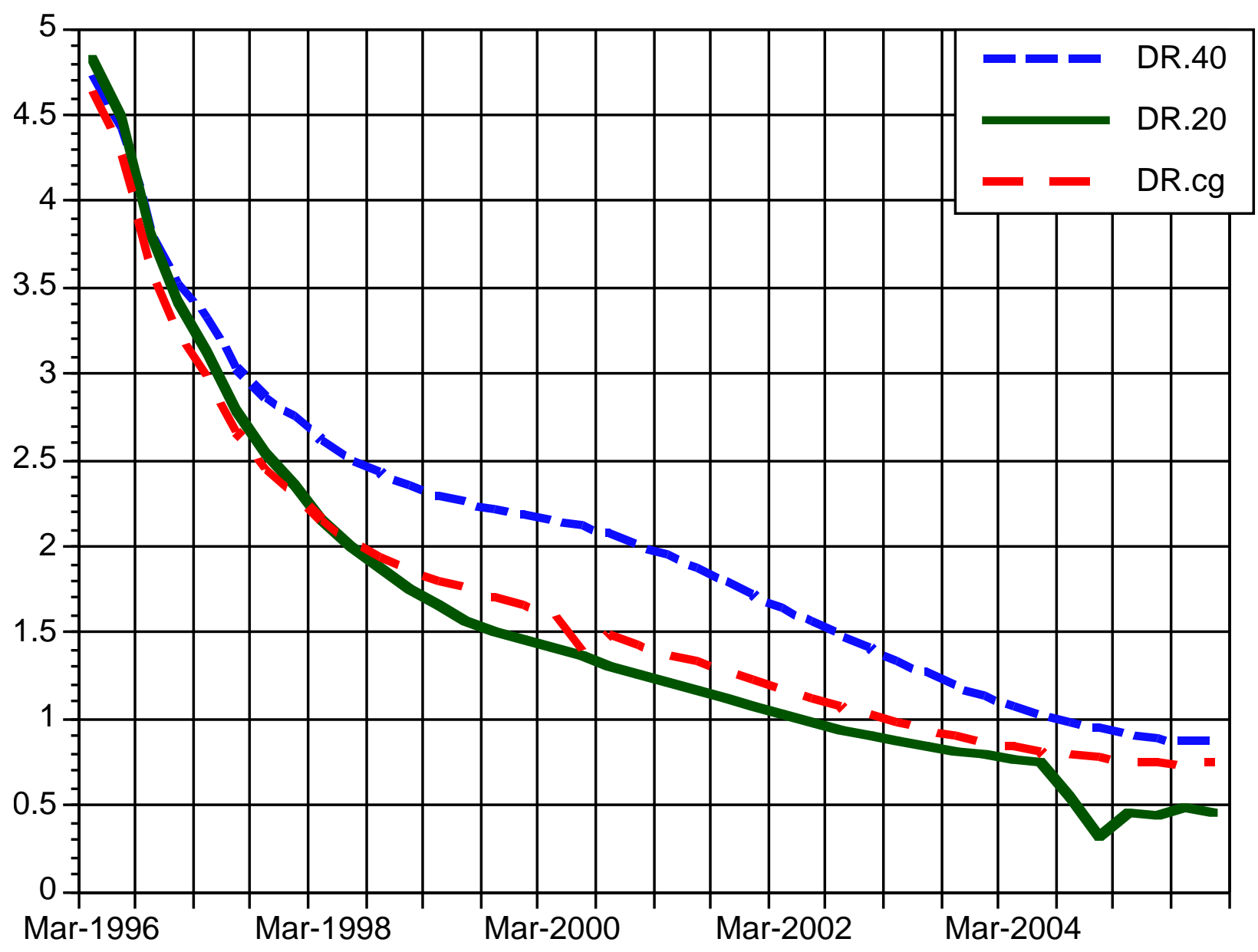


Figure 9

Cost of Change and Discount Rate for baseline experiment

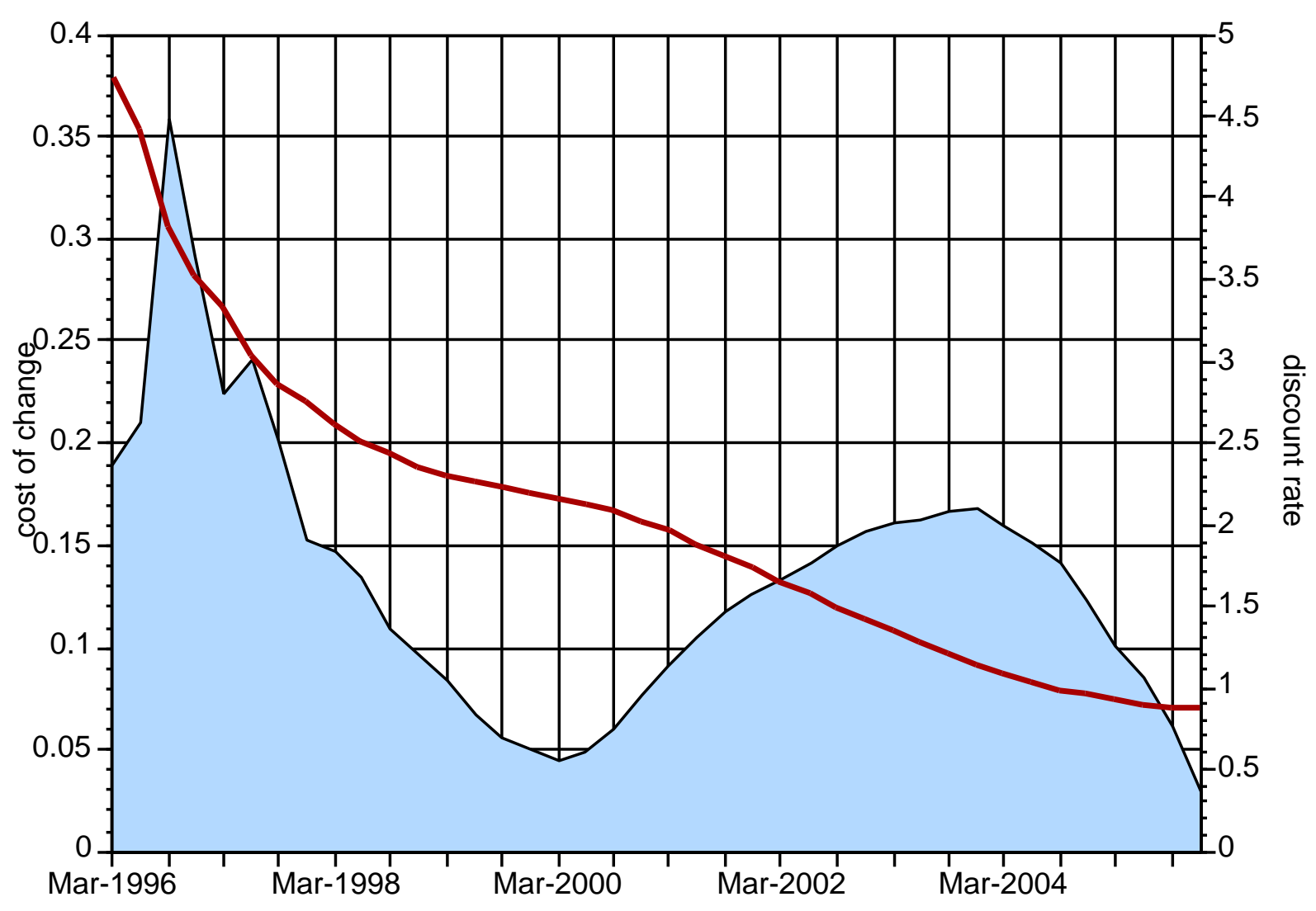

